\title{
Selective androgen receptor modulators: the future of androgen therapy?
}

\author{
Andrew R. Christiansen ${ }^{1}$, Larry I. Lipshultz ${ }^{2,3}$, James M. Hotaling ${ }^{4}$, Alexander W. Pastuszak ${ }^{4}$ \\ ${ }^{1}$ University of Utah School of Medicine, Salt Lake City, UT, USA; ${ }^{2}$ Scott Department of Urology; ${ }^{3}$ Center for Reproductive Medicine, Baylor \\ College of Medicine, Houston, TX, USA; ${ }^{4}$ Division of Urology, Department of Surgery, University of Utah School of Medicine, Salt Lake City, UT, \\ USA \\ Contributions: (I) Conception and design: AR Christiansen; (II) Administrative support: AW Pastuszak; (III) Provision of study material or patients: \\ AR Christiansen; (IV) Collection and assembly of data: AR Christiansen; (V) Data analysis and interpretation: AR Christiansen; (VI) Manuscript \\ writing: All authors; (VII) Final approval of manuscript: All authors. \\ Correspondence to: Alexander W. Pastuszak, MD, PhD. Assistant Professor, Division of Urology, Department of Surgery, University of Utah School of \\ Medicine, Salt Lake City, UT, USA. Email: alexander.pastuszak@hsc.utah.edu.
}

\begin{abstract}
Selective androgen receptor modulators (SARMs) are small molecule drugs that function as either androgen receptor (AR) agonists or antagonists. Variability in AR regulatory proteins in target tissues permits SARMs to selectively elicit anabolic benefits while eschewing the pitfalls of traditional androgen therapy. SARMs have few side effects and excellent oral and transdermal bioavailability and may, therefore, represent viable alternatives to current androgen therapies. SARMs have been studied as possible therapies for many conditions, including osteoporosis, Alzheimer's disease, breast cancer, stress urinary incontinence (SUI), prostate cancer (PCa), benign prostatic hyperplasia (BPH), male contraception, hypogonadism, Duchenne muscular dystrophy (DMD), and sarcopenia/muscle wasting/cancer cachexia. While there are no indications for SARMs currently approved by the Food and Drug Administration (FDA), many potential applications are still being explored, and results are promising. In this review, we examine the literature assessing the use of SARMS for a number of indications.
\end{abstract}

Keywords: Androgen receptor (AR); androgen therapy; selective androgen receptor modulator (SARM)

Submitted Sep 13, 2019. Accepted for publication Oct 31, 2019.

doi: $10.21037 /$ tau.2019.11.02

View this article at: http://dx.doi.org/10.21037/tau.2019.11.02

\section{SARMs: history and mechanisms}

Since their discovery near the close of the $20^{\text {th }}$ century (1), selective androgen receptor modulators (SARMs) have been heralded as the possible future of androgen therapy (2). As satisfaction, side effects, preparations, and perceptions have limited the utility of testosterone therapy (TTh), SARMs are poised to fundamentally alter the field of androgen therapy (2).

SARMs are chemically engineered small molecule drugs that can selectively exert varying degrees of agonist and antagonist effects on the androgen receptor (AR) throughout the body. Like androgens, SARMs enter the cytoplasm and bind to the AR. After translocating to the nucleus, the SARM-AR complex acts as a transcriptional regulator and recruits cofactors and coregulatory proteins, modulating the transcriptional response to binding of the AR complex $(3,4)$. While the AR is universally expressed, SARM-AR complexes can have varied effects due to variable cofactor recruitment (5). These complex configurations, along with tissue-dependent differences in AR expression patterns and regulatory milieu, allow for immense diversity of actions (4).

SARMs promise novel, convenient therapies that facilitate tissue-specific benefits without off-target side effects (6). Given the myriad drawbacks of TTh that can limit its use, including currently available formulations and common adverse effects, one can understand the excitement surrounding SARMs. Although still in the early stages of 
clinical evaluation, SARMs may one day be used in the treatment of hypogonadism in a form that is orally active with convenient dosing frequency, and that can provide the beneficial effects of TTh without the adverse effects (2).

In addition to their potential use for the treatment of hypogonadism $(7,8)$, SARMs are being explored as a potential therapy for osteopenia/osteoporosis (9-14), Alzheimer's disease (15), prostate cancer (PCa) $(16,17)$, benign prostatic hyperplasia $(\mathrm{BPH})(18)$, male contraception (19), breast cancer (20), stress-induced urinary incontinence (21), sarcopenia (22), muscular dystrophy $(23,24)$, and even cancer and chronic diseaserelated cachexia (25-30). While SARMs present an opportunity for therapy in several debilitating conditions, recently doubts concerning their ability to meet expectations have surfaced, especially concerning their utility in the treatment of cachexia.

Despite their potential to address significant unmet medical needs, regulatory roadblocks and poorly defined clinical study endpoints have tempered interest in the potential of SARMs for the first time since their discovery. Indeed, some now refer to the once-promising pathway to approval of SARMs as a "long and winding" one (31). More recently, the focus of using SARMs for cachexia has shifted to other clinical applications. The present review provides an overview of the developments in the literature and clinical trials on SARMs and offers a glimpse into the future therapeutic potential for SARMs.

\section{Methods}

A literature review was performed in the PubMed/Medline and ScienceDirect databases using the terms selective AR modulator, selective AR modulators, SARM, and SARMs. The initial search for literature resulted in 764 results. A total of 43 non-English language papers have been excluded. The remaining articles were screened for relevance and 97 were selected for inclusion in the review. Both basic and clinical studies have been included. Ongoing and recently concluded clinical trials listed on http://www.clinicaltrials. gov that are investigating SARMs were also reviewed and are compiled in Table 1.

\section{The AR \& SARMs}

The AR, a nuclear steroid hormone receptor and transcription factor, is found in both reproductive and nonreproductive tissues of the human body. However, while the AR itself is widely expressed throughout the human body, the cofactors required for modulation of AR activity are not. The variability in expression of these coregulatory components is complex and allows for tissue-specific, targeted therapeutic effects (5). The mechanisms of how SARM-AR complex activity and coregulation function to modulate gene expression and physiologic effects remain to be elucidated. The AR is essential both for its role in male sexual development and maintenance but also has the potential to alter bone density, strength, muscle mass, hematopoiesis, coagulation, metabolism, and cognition $(26,27)$. The complex regulatory environment of the AR allows selective receptor modulators (SRMs) to act as either agonists or antagonists, depending on the tissue and the expression of cofactors $(3,32)$.

The first class of SRMs to be discovered was Selective Estrogen Receptor Modulators (SERMs) (33), which are best known for their use in breast cancer treatment (tamoxifen). The successful development of SERMs charted a course for the manipulation of nuclear receptor signaling in both men and women, and has been followed by the discovery of SARMs (1), Selective Progesterone Receptor Modulators (SPRMs) (34), Selective Glucocorticoid Receptor Modulators (SGRMs) (35), Farnesoid X receptor modulators (36), and others.

Tissue selectivity is a critical distinction between classic steroid hormone therapy and AR modulation. While TTh offers benefits including gains in muscle mass and strength, it is associated with a high rate of adverse effects, partly due to off-target activation of AR in several tissues (4), and TTh currently lacks a highly effective oral formulation. TTh has also been associated with risks including testicular atrophy, erythrocytosis, dyslipidemia, gynecomastia, hepatotoxicity, and, in women, virilization and uterine hyperproliferation $(32,37,38)$. Meanwhile, SRMs/SARMs target AR function in specific tissues and cell types while minimizing effects on non-target tissues (6).

SARMs can be administered orally or transdermally (8), are mostly non-steroidal, and are capable of activating the $\mathrm{AR}$ in both muscle and bone. However, because they are not metabolized to dihydrotestosterone (DHT) by 5 -reductase, the risk of androgenic effects is reduced $(27,38)$. In addition, SARMs are not metabolized to estrogen by aromatase, limiting estrogenic effects (30). While the benefits of firstgeneration SARMs appear modest compared to those of androgens (39), the ability of SARMs to preferentially stimulate bone and muscle growth, shrink the prostate, and inhibit breast cancer growth without significant systemic 


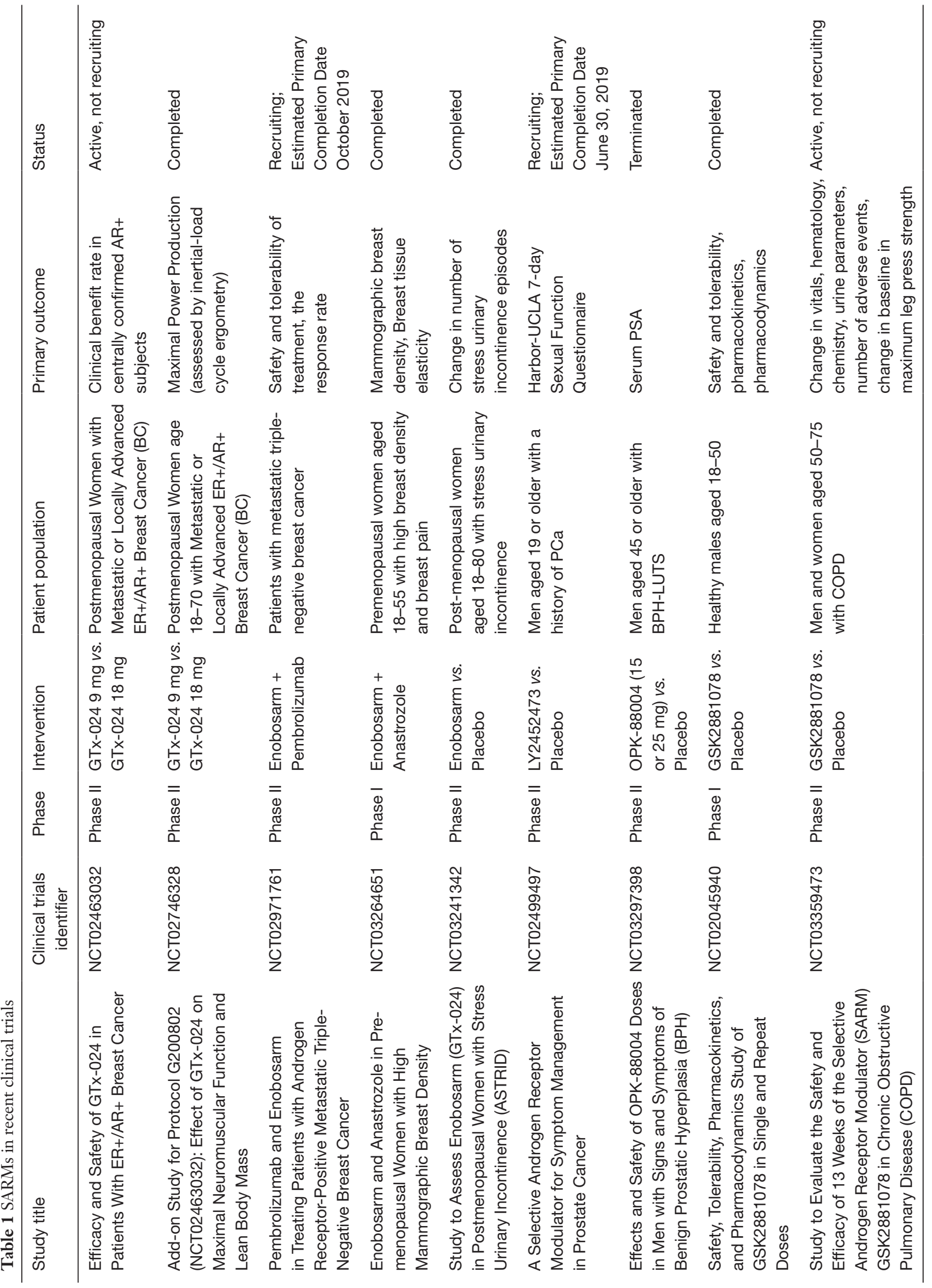


side effects is encouraging (40-46). Given that the treatment of many chronic diseases for which SARMs have been considered requires extended exposure, the apparent lack of significant adverse effects with SARMs as compared to androgens gives them a distinctive advantage.

\section{Current and future clinical applications of SARMs}

\section{Osteoporosis}

While existing therapies for osteoporosis are antiresorptive, capable of halting bone breakdown but not reversing the process, multiple SARMs have demonstrated the ability to promote new bone growth and increase bone strength in animal models $(9-13,47,48)$. Recently, four SARMs-BA321, YK11, ostarine, and LY305-have shown promise in the potential treatment of osteoporosis. These are listed in Table 2. BA321 can reverse bone loss without androgenic effects by binding to both AR and estrogen receptors (ER) in orchiectomized mice (13). Yatsu et al. described YK11, which can accelerate osteoblast cell proliferation via AR-mediated non-genomic activity (14). When mouse osteoblast cells (MC3T3-E1) were treated with YK11, it also promoted osteogenic activity, increased osteoblast-specific differentiation markers, and increased alkaline phosphatase (ALP) activity (a marker of osteoblast maturation) (14).

Hoffmann et al. investigated the bone-strengthening properties of ostarine (Enobosarm) in a rat model of postmenopausal osteoporosis (11). Eight weeks after ovariectomy, female rats were treated daily with low, intermediate, or high doses of ostarine for 5 weeks, with the low dose group showing no benefit, while the intermediate and high dose groups showing comparable improvements in microstructural indices including bone volume, density, and bone mineral density. These improvements were more significant in the femurs than in the vertebrae, although no significant improvements were observed in biomechanical properties (11).

In another study, LY305 reversed skeletal muscle atrophy and demonstrated increased bone formation in a bone fracture orchiectomized mouse model (8). LY305 was subsequently administered transdermally to humans in a phase I trial in order to circumvent high first-pass hepatic concentrations, which may contribute to dose-dependent suppression of high-density lipoprotein (HDL) observed with other oral SARMs $(27,28)$. In this study by Krishnan et al., men who applied increasing doses of LY305 gel to the axilla or trunk daily for up to 4 weeks experienced minimal adverse effects and saw no change in HDL levels or hematocrit (8). Utilizing transdermal delivery to limit or prevent alterations in HDL is a significant step forward for the utility and safety profile of SARMs, given that changes in HDL levels are the most significant adverse effect of SARMs observed to date.

\section{Alzheimer's disease}

Androgen depletion is implicated in the development of Alzheimer's disease, as circulating testosterone levels in older men are inversely correlated with levels of amyloid $\beta$ (A $\beta$ ) protein in the brain (15). Hypogonadal men also experience a decrease in cognitive processes including episodic memory, working memory, processing speed, visual-spatial processing, and executive function $(49,50)$, while a higher free testosterone index is associated with improved visual and verbal memory, visuospatial functioning, visual-motor scanning, and a lower rate of decline in visual memory (51). Given that these functions are regulated by AR-modulated regions of the brain (52), the potential impact of SARMs as a treatment for cognitive disorders associated with hypogonadism is significant. In 2013, the NEP28 SARM was found to increase the activity of an $A \beta$-degrading enzyme, neprilysin, without severe effects on the prostate (15). However, no further studies have investigated this compound.

\section{Breast cancer}

Improved breast cancer outcomes have been associated with increased androgen synthesis (53). However, androgens can also cause virilization in women. Being analogous to SERMs, which have differential effects on breast, bone, and uterine tissues (31), SARMs also exert their effects on breast tissue that expresses AR. Fortunately, improved breast cancer survival is correlated with AR expression (54), which occurs in up to $85 \%$ of ER-positive breast cancers and $95 \%$ of ER-negative breast cancers (55). This presents a unique opportunity for modulation by SARMs. In a press release from GTx Inc. regarding a recently completed phase II clinical trial (NCT02463032), Enobosarm slowed breast cancer growth in a subset of patients (20). Another ongoing phase II trial seeks to assess the treatment of AR-positive metastatic triple-negative breast cancer using cotherapy of pembrolizumab and Enobosarm (NCT02971761). Other 
Table 2 Potential applications of SARMs

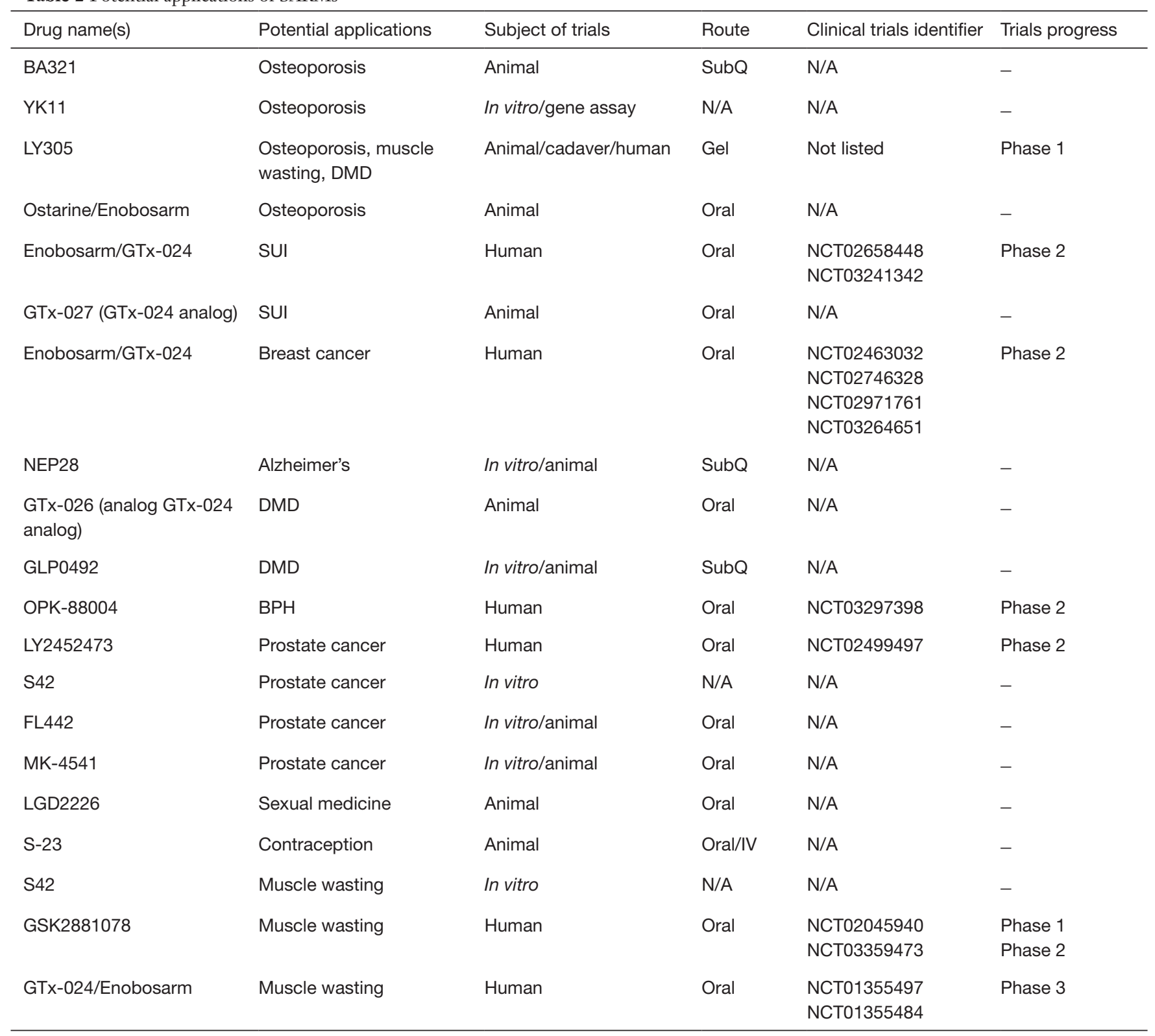

recently completed clinical trials examining SARM efficacy include: NCT02746328, which assessed the impact of 12-24 weeks of GTx-024 (Enobosarm) on neuromuscular function and lean body mass (LBM) in females with ER+/ AR+ breast cancer, and NCT03264651, a completed phase I study which studied the impact of a combination treatment of $9 \mathrm{mg}$ oral Enobosarm and $1 \mathrm{mg}$ oral anastrozole on reducing breast density.

\section{Stress urinary incontinence (SUI)}

The efficacy of SARMs on levator ani muscle weight has been used as a surrogate for anabolic activity in skeletal muscle (38). However, the levator ani is also a key muscle in the pathophysiology of SUI. As women age, circulating hormones are depleted postmenopausally and pelvic floor muscles atrophy. Lacking support of the pelvic organs and the lower urinary tract, difficulty with micturition results. 
Due to virilization and uterine hyperplasia, androgens are not an optimal treatment option for SUI, and presently no other medical therapies exist. Two SARMs, GTx024 (Enobosarm) and GTx-027 (GTx-024 analog), have demonstrated preclinical potential for the treatment of SUI by selectively increasing pelvic floor mass in an ovariectomized mouse model (21). Reversal of muscle loss in post-menopausal mice was accompanied by a substantial downregulation of genes linked to muscle catabolism. This study presented a step toward the clinical evaluation of SARMs for the treatment of SUI, a problem that affects up to $35 \%$ of adult women (56).

Following a promising proof of concept study, a phase II clinical trial (NCT03241342; ASTRID) of GTx-024 was initiated. Post-menopausal women were placed on either placebo, $1 \mathrm{mg}$, or $3 \mathrm{mg}$ oral GTx-024 therapy, and change in stress continence episodes from baseline was examined (57). Unfortunately, the study failed to meet its primary endpoint of achieving a $50 \%$ reduction in SUI daily episodes compared to the placebo. Two subsequent phase II studies (NCT03566290, NCT03508648) were terminated the same month, per http://www.clinicaltrials.gov. As such, the role of SARMs in the treatment of SUI is currently undefined.

\section{Pca}

Controversy still exists regarding whether TTh may stimulate latent PCa, limiting the application of TTh in the treatment of hypogonadism in men with a history of PCa $(4,17)$. Solomon et al. recently reviewed two SARMs, FL442 and MK-4541, which have been tested/explored as treatments for PCa. FL442 acted as an AR antagonist in the PCa cell models with efficacy comparable to that of enzalutamide $(4,58)$. Meanwhile, MK-4541 induced apoptosis in androgen-independent, AR-positive PCa cell lines (59).

The S42 SARM has emerged as a prospective treatment for PCa. Upon its initial discovery, S42 was observed to have anabolic effects on muscle while sparing the prostate (60). Only years later was its potential for PCa treatment considered in its suppression of PCa cell proliferation signaling components, including the 5-DHT-induced (extracellular signal-regulated kinase (ERK)-mitogenactivated protein kinase (MAPK) pathway $(17,61)$. In addition, 542 inhibited tumor growth by limiting the expression of prostate-specific antigen (PSA), P504S, Ki67, and phosphorylated ERK-MAPK (17). S42 also attenuated proliferation-related receptors, including insulin-like growth factor-1 receptor (IGF-1R), insulin receptor, and the AR. While S42 reduced tumor growth and antagonized DNA replication in PCa cells, it did not induce apoptosis (17). One phase II clinical trial (NCT02499497) is investigating the efficacy of the SARM LY2452473 in improving symptom management in men with $\mathrm{PCa}$, including sexual function, quality of life, and muscle and bone mass.

SARMs may also be used in the setting of $\mathrm{PCa}$ management for the targeted imaging of prostate tissue (62). Given the expression of the AR in every stage of $\mathrm{PCa}$ evolution, radioactively-labeled SARMs could be used for the radiological diagnosis of metastatic disease (63). These findings suggest another future benefit of SARMs in the evaluation and treatment of PCa.

\section{BPH}

One can envision the potential utility of SARMs as a treatment for BPH by acting as an AR antagonist. Zilbermint et al. observed that because SARMs are not metabolized to DHT by 5 -reductase, the risk of prostatic hyperplasia is reduced (30). While previous studies have observed that SARMs can decrease prostatic weight in rat models $(18,43)$, a single phase II clinical trial (NCT03297398) was recently initiated to study the efficacy and safety of OPK-88004 in men with BPH. In the trial, patients were treated with either a placebo, 15 , or $25 \mathrm{mg}$ of OPK-88004 for 16 weeks. Monthly visits evaluated drug safety and plasma levels, as well as its effect on prostate size and lower urinary tract symptoms (LUTS). Unfortunately, this trial has since been terminated, and a press release disclosed that while serum PSA analysis has yet to be completed, the utilization of transrectal ultrasound for measuring prostate volume proved to be too imprecise to reliably determine the effect of the drug (64). In addition, transient increases in liver enzymes were observed in several men in the trial.

\section{Male contraception}

The prospect of SARMs as a method of male contraception has been yet another focus of investigation, especially given their apparent lack of significant side effects. Animal studies of two SARMs, C-6 and S-23, were examined by Solomon et al. in a recent review (4). In mouse models, S-23 demonstrated the potential to reversibly suppress spermatogenesis while also increasing lean muscle mass, bone mineral density, and decreasing fat mass (65). While 
SARM development appears to be focused on other areas of intervention, these preliminary findings are promising.

\section{Hypogonadism and sexual medicine}

SARMs may represent a promising potential alternative to TTh, which has been the mainstay of the treatment of hypogonadism. While the sexual benefits of TTh are well established, unlike exogenous testosterone, SARMs are orally active, nonaromatizable, non-virilizing, and tissueselective, with a better side effect profile than TTh (66). Previous studies have demonstrated the potential benefit of SARMs for libido in both female and male rats $(67,68)$. In one study, treatment of male rats with the SARM LGD2226 resulted in an increased number of mounts, intromissions, and ejaculations compared with a control group (68). These results did not differ significantly from a group treated with the synthetic androgen, fluoxymesterone, suggesting that SARMs may represent a viable alternative to TTh in promoting male libido (4).

As elaborated upon in other sections of this review, many SARMs have shown the potential to treat male hypogonadal symptoms such as deficits in muscle mass and bone mineral density $(10,69)$. Among others, the SARMs enobosarm and LY305 have shown the capacity to reverse the hypogonadalrelated decline of muscle mass and bone density. LY305 did so while simultaneously avoiding adverse effects demonstrated by other SARMs such as decreased HDL and increased hematocrit. However, approval for SARMs in the treatment of male hypogonadism likely hinges upon "defining what constitutes a clinical deficit in these bypogonadal symptoms, and...defining what qualifies as a clinical benefit in ameliorating them" (31).

\section{Duchenne muscular dystrophy (DMD)}

DMD is a crippling genetic disorder that causes progressive muscle wasting and weakness because of mutations in the cytoskeletal protein dystrophin. Corticosteroids are currently the standard of care, but one side effect of their prolonged use is muscle wasting. The anabolic benefits of SARMs to muscle and bone without off-target androgenic side effects provides a distinct advantage to androgens. Previous work found that GLP0492 can increase body weight, muscle mass, diaphragm contractile force, and running performance in mice $(4,23)$. In addition, as noted previously, LY305 reversed skeletal muscle atrophy by utilizing transdermal delivery, thus avoiding a rise in HDL.
In a comprehensive study, Ponnusamy et al. hypothesized that the absence of anabolic androgen activity exacerbated the rapidly diminishing health of young boys with DMD and that SARM treatment could reverse the decline in physical function and prolong life (24). When GTx026, an analog of GTx-024, was used in castrated and dystrophin mutant mice, a decrease in fibrosis and increases in cardiopulmonary function, body weight, lean mass, grip strength, and survival were observed (24). GTx-026 was found to exert its effects through a pathway distinct from dystrophin-regulated pathways (24). In addition, SARM treatment had the potential to improve muscle regeneration, as measured by a reduction in centrally nucleated muscle cells (24).

\section{Muscle wasting}

The use of SARMs as a potential alternative to TTh for cancer-related cachexia or age-related sarcopenia has been desirable since their discovery $(2,28,70)$. Due to their selective anabolic activity without associated androgenic side effects, SARMs may treat muscle wasting associated with many chronic conditions including heart failure, chronic obstructive pulmonary disease (COPD), HIV, end-stage liver and kidney disease, chronic infection, immobilization, and chronic glucocorticoid use $(4,69,71)$. Studies have demonstrated that survival of cancer patients correlates directly with muscle mass (72-74) and that sarcopenia is associated with increased mortality (75). As such, testosterone is approved for the treatment of these conditions. However, recent clinical trials have suggested that the cardiac risks of TTh outweigh its therapeutic benefits $(76,77)$. Although this controversy has not been resolved, SARMs are being considered instead of TTh to address the problem of muscle wasting. While early preclinical models showed SARMs to be effective in ameliorating muscle wasting by increasing lean body mass, recent clinical studies have cast doubt on their outlook.

Several phase I studies have recently evaluated the safety, tolerability, pharmacokinetics, and pharmacodynamics of the SARM GSK2881078. In a study by Clark et al. (NCT02045940), a dose range of oral GSK2881078 was administered to healthy men and postmenopausal women for either 7 or 14 days and was associated with decreases in HDL, similar to what has been observed with other SARMs $(4,19,78)$. Adverse events were noted in half of the study population, though these were distributed evenly between the placebo and active treatment groups, indicating that 
the dose range was well tolerated (78). These early trials demonstrate a potential role for GSK2881078 in cachexia therapy.

In another phase I clinical investigation of GSK2881078, gains in lean mass were evaluated at various doses (29). While both male and female patients on all doses of GSK2881078 experienced greater lean mass gains than those on placebo, lower doses resulted in greater lean mass responses in females than in males (29). These dose-dependent gains were produced in the absence of any resistance training. Transient elevations in alanine aminotransferase (ALT) were observed but resolved despite continuing the drug, and reversible reductions in testosterone levels were observed in all men. Finally, a phase II trial (NCT03359473) evaluating the efficacy and safety of GSK2881078 in COPD is currently underway. In addition to safety, this trial is evaluating the effects of GSK2881078 on physical strength and function in both postmenopausal female and older male subjects with COPD and muscle weakness. These subjects will participate in a baseline period for 30 days, after which they will follow a home exercise program and treatment for 13 weeks, followed by a 6-week follow-up period during which subjects' performance in various trials will be evaluated, such as leg press strength and vitals.

A recent study by Muta et al. examined the impact of a novel SARM, S42, on the muscle cell line $\mathrm{C} 2 \mathrm{C} 12$ in vitro, which was observed to have anabolic and anti-catabolic effects on myotubes of differentiating muscle cells (22). The anti-catabolic effects consisted of inhibition of the degradation pathway in C2C12 myotubes and decreased expression of skeletal muscle ubiquitin ligase. The anabolic effects of S42 included activation of the mTORC1-p70S6K signaling pathway, independent of IGF-1-Akt signaling. S42 may selectively encourage muscle growth while simultaneously minimizing certain undesirable effects such as prostate growth (22). These in vitro results hint at the ability of SARMs to both prevent muscle loss and induce muscle gains in patients who suffer from muscle wasting conditions.

Unfortunately, results of recent clinical trials of the SARM GTx-024 (Enobosarm) have tempered expectations for its utility as a therapy for muscle wasting. Early on, GTx-024 appeared to have a very bright future as a treatment for sarcopenia/cachexia. Preliminary clinical trials demonstrated that $\mathrm{GTx}$ - 024 could increase lean body mass and improve physical function without androgenic side effects (27). However, Enobosarm was dealt a blow after the phase III Prevention and treatment Of muscle Wasting in patients with cancER (POWER) I and II trials, where increases in lean body mass were once again observed, but without improved stair climb power $(79,80)$. Failure to attain both primary endpoints led to a lack of approval by the Food and Drug Administration (FDA), which has cast doubt on the previously charted course for SARMs and has tempered enthusiasm regarding the role of SARMs in the treatment of muscle wasting conditions.

\section{Cachexia controversy}

In 2015, Bhasin noted that "functional exercise training may be necessary to translate the physiological benefits of SARMs into functional improvements" (39). Indeed, following the recent challenges for SARMs and cachexia, a similar concern was shared by Ramage \& Skipworth, who noted that "The relationship between muscle mass and muscle function is complex and unlikely to be linear" (80). Again, Dalton et al. lamented that "proving that SARM-induced increases in lean body mass (i.e., muscle) are associated with improvements in physical function appears to the greatest barrier to their regulatory approval and clinical use" (31).

While the results of the phase III POWER trials demonstrated that Enobosarm (GTx-024) could induce measurable and meaningful gains in lean body mass, there was no significant accompanying improvement in physical function (31). Presumably, this is due to confounding factors including age, disease stage, baseline physical function, and chemotherapy, but the fact remains that a definitive correlation between lean body mass and physical function in a large patient population has "remained elusive for a SARM" (31). This barrier, however, extends beyond just SARMs. At this time, no drug has been approved by the FDA to treat cancer cachexia (71). Indeed, in the ROMANA anamorelin trials, significant increases in LBM were not accompanied by gains in handgrip strength (81). Therefore, in trials of both Enobosarm and anamorelin, despite measurable gains in LBM, lack of correlated improvements in physical function resulted in a negative regulatory interpretation of the trials and lack of FDA approval (71). Merely preventing a decline in performance was also not considered to be an acceptable outcome (82).

One of the most significant obstacles for approval of SARMs as a future treatment for cachexia is both a lack of consensus on proper endpoints for clinical trials and a drought of regulatory direction $(71,82)$. Unfortunately, these shortfalls have led to the standstill of many promising 
drugs in spite of a significant unmet medical need (71). Given that cachexia is defined by the presence of three essential elements: muscle loss and change in body composition, impaired nutrition, and decline in physical function (83), it has been suggested that treatment best be evaluated simply by patient responses to these domains. It should be noted that, despite the logic that proper nutrition be accompanied by exercise to achieve functional gains, one systematic review found "insufficient evidence in the safety and effectiveness of exercise in cancer cachexia patients" (84). Therefore, the requirement that a SARM must improve physical function in order to gain approval may be unreasonable. As such, to push forward with welldesigned clinical trials that further define the efficacy of SARMs in cachexia and sarcopenia, appropriate clinical trial endpoints must be developed.

\section{Potential for abuse}

Performance-enhancing drugs, such as exogenous testosterone, have long been a concern in professional athletics and have resulted in anti-doping measures. SARMs, with their attractive side effect profile, ease of use, and relative difficulty to detect compared to other androgenic compounds, present a significant potential for abuse $(85,86)$. Indeed, despite not being approved by the FDA, SARMs are readily available for purchase online (4). However, though marketed as SARMs, one study found that many of these online offerings are inaccurately labeled and contain unapproved substances, with only $52 \%$ containing the active SARM (87). Conversely, ostarine has been found as both a listed and unlisted ingredient in many dietary supplements (88).

As such, efforts are currently focused on continuing to isolate metabolites from novel SARMs for drug testing $(89,90)$, and multiple SARMs have already been added by the World Anti-Doping Agency (WADA) to the Prohibited List (91). Consequently, several athletes have been suspended for testing positive for SARM metabolites; an NBA athlete was recently suspended for taking LGD4033 (92), while an NCAA basketball player and four UFC fighters have been penalized for trace amounts of ostarine (Enobosarm) in their systems $(88,93)$. As novel SARMs are discovered and become available, regulating their use may become a challenge. Furthermore, once FDA approval occurs, significant potential for off-label use is likely, depending on the drug and its effects.

\section{Conclusions}

Widely expressed throughout the human body, the AR plays a role in sexual development and many other processes such as growth and maintenance of muscle and bone. Tissue-dependent patterns of AR expression, along with varied transcriptional coregulation, allow for diversity of actions when the AR is combined with its ligand. SARMs are chemically engineered drugs that can selectively exert varying degrees of agonist and antagonist effects on the AR, depending on their structure. This allows for targeted therapeutic benefits with the absence of adverse off-target effects, which is currently a significant limitation of TTh. SARMs are well tolerated, and their oral bioavailability provides a substantial advantage over other methods of androgen therapy. Finally, the potential for transdermal administration may circumvent hepatic metabolism and negate decreases in HDL, one of the only significant side effects of SARMs observed to date.

SARMs have demonstrated the ability to preferentially stimulate bone and muscle growth, shrink the prostate, and inhibit breast cancer growth. This variety of tissue selectivity may enable SARMs to treat a wide range of diseases, from muscle wasting and osteoporosis to hypogonadism and $\mathrm{BPH}$. However, while SARMs have shown potential to ameliorate numerous serious and therapy-deficient pathologies, much remains to be examined regarding their efficacy, and regulatory approval remains elusive. The future use of SARMs for treatment of cachexia is currently tentative because of a lack of consensus regarding endpoints for clinical trials. As such, the future of SARMs may hinge on their use for other indications such as PCa, breast cancer, and osteoporosis. Nevertheless, there is still considerable confidence that SARMs have the potential to provide revolutionary treatment for diverse medical challenges.

\section{Acknowledgments}

Funding: AW Pastuszak is a National Institutes of Health (NIH) K08 Scholar supported by a Mentored Career Development Award (K08DK115835-01) from the National Institute of Diabetes and Digestive and Kidney Diseases. This work is also supported in part through a Urology Care Foundation Rising Stars in Urology Award (to AW Pastuszak). The content is solely the responsibility of the authors and does not necessarily represent the official views of the NIH. 


\section{Footnote}

Provenance and Peer Review: This article was commissioned by the Guest Editors (Larry I. Lipshultz, Alexander W. Pastuszak) for the focused issue "Contemporary Issues and Controversies in Men's Health" published in Translational Andrology and Urology. The article was sent for external peer review organized by the Guest Editors and the editorial office.

Conflicts of Interest: The focused issue "Contemporary Issues and Controversies in Men's Health" was commissioned by the editorial office without any funding or sponsorship. LIL serves as an unpaid editorial board member of Translational Andrology and Urology from Nov 2019 to Oct 2021. LIL and AWP served as the unpaid Guest Editors of the focused issue. JMH serves as an unpaid editorial board member of Translational Andrology and Urology from Aug 2019 to Jul 2021. AW Pastuszak: Endo Pharmaceuticals - advisor, consultant, speaker, research support; Boston Scientific - advisor; Antares Pharmaceuticals - advisor; Bayer AGspeaker. JM Hotaling: Endo pharmaceuticals - research support, educational grant; Boston Scientific - educational grant; StreamDx, Inherent Biosciences, Andro360, Nanonc - equity/founder of early stage startups; Turtle Health advisor. The other authors have no conflicts of interest to declare.

Ethical Statement: The authors are accountable for all aspects of the work in ensuring that questions related to the accuracy or integrity of any part of the work are appropriately investigated and resolved.

Open Access Statement: This is an Open Access article distributed in accordance with the Creative Commons Attribution-NonCommercial-NoDerivs 4.0 International License (CC BY-NC-ND 4.0), which permits the noncommercial replication and distribution of the article with the strict proviso that no changes or edits are made and the original work is properly cited (including links to both the formal publication through the relevant DOI and the license). See: https://creativecommons.org/licenses/by-nc$\mathrm{nd} / 4.0 /$.

\section{References}

1. Dalton JT, Mukherjee A, Zhu Z, et al. Discovery of nonsteroidal androgens. Biochem Biophys Res Commun
1998;244:1-4.

2. Negro-Vilar As. Selective Androgen Receptor Modulators (SARMs): A Novel Approach to Androgen Therapy for the New Millennium. J Clin Endocrinol Metab 1999;84:3459-62.

3. Hikichi Y, Yamaoka M, Kusaka M, et al. Selective androgen receptor modulator activity of a steroidal antiandrogen TSAA-291 and its cofactor recruitment profile. Eur J Pharmacol 2015;765:322-31.

4. Solomon ZJ, Mirabal JR, Mazur DJ, et al. Selective Androgen Receptor Modulators: Current Knowledge and Clinical Applications. Sex Med Rev 2019;7:84-94.

5. Miller CP, Shomali M, Lyttle CR, et al. Design, Synthesis, and Preclinical Characterization of the Selective Androgen Receptor Modulator (SARM) RAD140. ACS Med Chem Lett 2010;2:124-9.

6. Handlon AL, Schaller LT, Leesnitzer LM, et al. Optimizing Ligand Efficiency of Selective Androgen Receptor Modulators (SARMs). ACS Medicinal Chemistry Letters 2015;7:83-8.

7. Carrasquillo R, Chu K, Ramasamy R. Novel Therapy for Male Hypogonadism. Curr Urol Rep 2018;19:63.

8. Krishnan V, Patel NJ, Mackrell JG, et al. Development of a selective androgen receptor modulator for transdermal use in hypogonadal patients. Andrology 2018;6:455-64.

9. Gao W, Reiser PJ, Coss CC, et al. Selective Androgen Receptor Modulator Treatment Improves Muscle Strength and Body Composition and Prevents Bone Loss in Orchidectomized Rats. Endocrinology 2005;146:4887-97.

10. Hanada K, Furuya K, Yamamoto N, et al. Bone Anabolic Effects of S-40503, a Novel Nonsteroidal Selective Androgen Receptor Modulator (SARM), in Rat Models of Osteoporosis. Biol Pharm Bull 2003;26:1563-9.

11. Hoffmann DB, Komrakova M, Pflug S, et al. Evaluation of ostarine as a selective androgen receptor modulator in a rat model of postmenopausal osteoporosis. J Bone Miner Metab 2019;37:243-55.

12. Kearbey JD, Gao W, Narayanan R, et al. Selective Androgen Receptor Modulator (SARM) Treatment Prevents Bone Loss and Reduces Body Fat in Ovariectomized Rats. Pharm Res 2007;24:328-35.

13. Watanabe K, Hirata M, Tominari T, et al. BA321, a novel carborane analog that binds to androgen and estrogen receptors, acts as a new selective androgen receptor modulator of bone in male mice. Biochem Biophys Res Commun 2016;478:279-85.

14. Yatsu T, Kusakabe T, Kato K, et al. Selective Androgen 
Receptor Modulator, YK11, Up-Regulates Osteoblastic Proliferation and Differentiation in MC3T3-E1 Cells. Biol Pharm Bull 2018;41:394-8.

15. Akita K, Harada K, Ichihara J, et al. A novel selective androgen receptor modulator, NEP28, is efficacious in muscle and brain without serious side effects on prostate. Eur J Pharmacol 2013;720:107-14.

16. Chisamore MJ, Gentile MA, Dillon GM, et al. A novel selective androgen receptor modulator (SARM) MK4541 exerts anti-androgenic activity in the prostate cancer xenograft R-3327G and anabolic activity on skeletal muscle mass \& function in castrated mice. J Steroid Biochem Mol Biol 2016;163:88-97.

17. Kawanami T, Tanaka T, Hamaguchi Y, et al. Selective Androgen Receptor Modulator S42 Suppresses Prostate Cancer Cell Proliferation. Endocrinology 2018;159:1774-92.

18. Nejishima H, Yamamoto N, Suzuki M, et al. Antiandrogenic effects of S-40542, a novel non-steroidal selective androgen receptor modulator (SARM) for the treatment of benign prostatic hyperplasia. Prostate 2012;72:1580-7.

19. Chen J, Hwang DJ, Bohl CE, et al. A selective androgen receptor modulator for hormonal male contraception. J Pharmacol Exp Ther 2005;312:546-53.

20. GTx Reports Results from Ongoing Enobosarm Phase 2 Clinical Trial in ER+/AR+ Breast Cancer., Biospace. 2016. Available online: https://www.biospace.com/ article/releases/gtx-corp-reports-results-from-ongoingenobosarm-phase-2-clinical-trial-in-er-ar-breast-cancer-/

21. Ponnusamy S, Sullivan RD, Thiyagarajan T, et al. Tissue Selective Androgen Receptor Modulators (SARMs) Increase Pelvic Floor Muscle Mass in Ovariectomized Mice. J Cell Biochem 2017;118:640-6.

22. Muta Y, Tanaka T, Hamaguchi Y, et al. Selective androgen receptor modulator, $\mathrm{S} 42$ has anabolic and anti-catabolic effects on cultured myotubes. Biochem Biophys Rep 2019;17:177-81.

23. Cozzoli A, Capogrosso RF, Sblendorio VT, et al. GLPG0492, a novel selective androgen receptor modulator, improves muscle performance in the exercisedmdx mouse model of muscular dystrophy. Pharmacol Res 2013;72:9-24.

24. Ponnusamy S, Sullivan RD, You D, et al. Androgen receptor agonists increase lean mass, improve cardiopulmonary functions and extend survival in preclinical models of Duchenne muscular dystrophy. Human Molecular Genetics 2017;26:2526-40.
25. Advani SM, Advani PG, VonVille HM, et al.

Pharmacological management of cachexia in adult cancer patients: a systematic review of clinical trials. BMC Cancer 2018;18:1174.

26. Crawford J, Prado CM, Johnston MA, et al. Study Design and Rationale for the Phase 3 Clinical Development Program of Enobosarm, a Selective Androgen Receptor Modulator, for the Prevention and Treatment of Muscle Wasting in Cancer Patients (POWER Trials). Curr Oncol Rep 2016;18:37.

27. Dalton JT, Barnette KG, Bohl CE, et al. The selective androgen receptor modulator GTx-024 (enobosarm) improves lean body mass and physical function in healthy elderly men and postmenopausal women: results of a double-blind, placebo-controlled phase II trial. J Cachexia Sarcopenia Muscle 2011;2:153-61.

28. Dobs AS, Boccia RV, Croot CC, et al. Effects of enobosarm on muscle wasting and physical function in patients with cancer: a double-blind, randomised controlled phase 2 trial. Lancet Oncol 2013;14:335-45.

29. Neil D, Clark RV, Magee M, et al. GSK2881078, a SARM, Produces Dose-Dependent Increases in Lean Mass in Healthy Older Men and Women. J Clin Endocrinol Metab 2018;103:3215-24.

30. Zilbermint MF, Dobs AS. Nonsteroidal selective androgen receptor modulator Ostarine $\mathrm{TM}^{\mathrm{TM}}$ in cancer cachexia. Future Oncol 2009;5:1211-20.

31. Dalton JT. The long and winding road for selective androgen receptor modulators. Br J Clin Pharmacol 2017;83:2131-3.

32. Unwalla R, Mousseau JJ, Fadeyi OO, et al. StructureBased Approach To Identify 5-[4-Hydroxyphenyl] pyrrole-2-carbonitrile Derivatives as Potent and Tissue Selective Androgen Receptor Modulators. J Med Chem 2017;60:6451-7.

33. Charles D, Barr W, Bell ET, et al. Clomiphene in the treatment of oligomenorrhea and amenorrhea. Am J Obstet Gynecol 1963;86:913-22.

34. Tabata Y, Iizuka Y, Shinei R, et al. CP8668, a novel orally active nonsteroidal progesterone receptor modulator with tetrahydrobenzindolone skeleton. Eur J Pharmacol 2003;461:73-8.

35. Link JT, Sorensen B, Patel J, et al. Antidiabetic Activity of Passive Nonsteroidal Glucocorticoid Receptor Modulators. J Med Chem 2005;48:5295-304.

36. Fang S, Suh JM, Reilly SM, et al. Intestinal FXR agonism promotes adipose tissue browning and reduces obesity and insulin resistance. Nature Med 2015;21:159. 
37. Basaria S, Coviello AD, Travison TG, et al. Adverse events associated with testosterone administration. N Engl J Med 2010;363:109-22.

38. Narayanan R, Coss CC, Dalton JT. Development of selective androgen receptor modulators (SARMs). Mol Cell Endocrinol 2018;465:134-42.

39. Bhasin S. Selective Androgen Receptor Modulators as Function Promoting Therapies. The J Frailty Aging 2015;4:121-2.

40. Bohl CE, Wu Z, Chen J, et al. Effect of B-ring substitution pattern on binding mode of propionamide selective androgen receptor modulators. Bioorg Med Chem Lett 2008;18:5567-70.

41. Furuya K, Yamamoto N, Ohyabu Y, et al. Mechanism of the tissue-specific action of the selective androgen receptor modulator S-101479. Biol Pharm Bull 2013;36:442-51.

42. Gao W, Dalton JT. Ockham's razor and selective androgen receptor modulators (SARMs): are we overlooking the role of 5alpha-reductase? Mol Interv 2007;7:10-3.

43. Gao W, Kearbey JD, Nair VA, et al. Comparison of the pharmacological effects of a novel selective androgen receptor modulator, the 5alpha-reductase inhibitor finasteride, and the antiandrogen hydroxyflutamide in intact rats: new approach for benign prostate hyperplasia. Endocrinology 2004;145:5420-8.

44. Kazmin D, Prytkova T, Cook CE, et al. Linking ligandinduced alterations in androgen receptor structure to differential gene expression: a first step in the rational design of selective androgen receptor modulators. Mol Endocrinol 2006;20:1201-17.

45. Narayanan R, Ahn S, Cheney MD, et al. Selective androgen receptor modulators (SARMs) negatively regulate triple-negative breast cancer growth and epithelial:mesenchymal stem cell signaling. PLoS One 2014;9:e103202.

46. Narayanan R, Coss CC, Yepuru M, et al. Steroidal androgens and nonsteroidal, tissue-selective androgen receptor modulator, S-22, regulate androgen receptor function through distinct genomic and nongenomic signaling pathways. Mol Endocrinol 2008;22:2448-65.

47. Discovery and preclinical profile of a highly potent and muscle selective androgen receptor modulator (SARM). Available online: https://www.acsmedchem.org/ama/orig/ abstracts/mediabstracts2004.pdf

48. Mohler ML, Nair VA, Hwang DJ, et al. Nonsteroidal tissue selective androgen receptor modulators: a promising class of clinical candidates. Expert Opinion on Therapeutic Patents 2005;15:1565-85.

49. Ciocca G, Limoncin E, Carosa E, et al. Is Testosterone a Food for the Brain? Sex Med Rev 2016;4:15-25.

50. Holland J, Bandelow S, Hogervorst E. Testosterone levels and cognition in elderly men: a review. Maturitas 2011;69:322-37.

51. Moffat SD, Zonderman AB, Metter EJ, et al. Longitudinal Assessment of Serum Free Testosterone Concentration Predicts Memory Performance and Cognitive Status in Elderly Men. J Clin Endocrinol Metab 2002;87:5001-7.

52. Burkhardt MS, Foster JK, Clarnette RM, et al. Interaction between Testosterone and Apolipoprotein E $\& 4$ Status on Cognition in Healthy Older Men. J Clin Endocrinol Metab 2006;91:1168-72.

53. McNamara KM, Yoda T, Miki Y, et al. Androgenic pathway in triple negative invasive ductal tumors: Its correlation with tumor cell proliferation. Cancer Science 2013;104:639-46.

54. Sultana A, Idress R, Naqvi ZA, et al. Expression of the androgen receptor, pAkt, and pPTEN in breast cancer and their potential in prognostication. Transl Oncol 2014;7:355-62.

55. Vontela N, Koduri V, Schwartzberg LS, et al. Selective Androgen Receptor Modulator in a Patient With Hormone-Positive Metastatic Breast Cancer. J Natl Compr Canc Netw 2017;15:284.

56. Luber KM. The definition, prevalence, and risk factors for stress urinary incontinence. Rev Urol 2004;6 Suppl 3:S3-9.

57. GTx's Enobosarm Fails Phase II Trial in Stress Urinary Incontinence; Stock Plunges 90\%+. Genetic Engineering \& Biotechnology News (GEN). 2018. Available online: https://www.genengnews.com/news/gtxs-enobosarmfails-phase-ii-trial-in-stress-urinary-incontinence-stockplunges-90/

58. Poutiainen PK, Huhtala T, Jääskeläinen T, et al. Preclinical pharmacology of FL442, a novel nonsteroidal androgen receptor modulator. Mol Cell Endocrinol 2014;387:8-18.

59. Schmidt A, Meissner RS, Gentile MA, et al. Identification of an anabolic selective androgen receptor modulator that actively induces death of androgen-independent prostate cancer cells. J Steroid Biochem Mol Biol 2014;143:29-39.

60. Gao $\mathrm{W}, \mathrm{Wu} Z$, Bohl CE, et al. Characterization of the in vitro metabolism of selective androgen receptor modulator using human, rat, and dog liver enzyme preparations. Drug 
Metab Dispos 2006;34:243-53.

61. Min L, Yanase T, Tanaka T, et al. A novel synthetic androgen receptor ligand, S42, works as a selective androgen receptor modulator and possesses metabolic effects with little impact on the prostate. Endocrinology 2009;150:5606-16.

62. Yang J, Wu Z, Wu D, et al. Pharmacokinetics, biodistribution and metabolism of a novel selective androgen receptor modulator designed for prostate cancer imaging. Int J Oncol 2010;36:213-22.

63. Schmidt A, Kimmel DB, Bai C, et al. Discovery of the selective androgen receptor modulator MK0773 using a rational development strategy based on differential transcriptional requirements for androgenic anabolism versus reproductive physiology. J Biol Chem 2010;285:17054-64.

64. OPKO Provides Update on the Development of OPK88004, a Selective Androgen Receptor Modulator. 2019.

65. Jones A, Chen J, Hwang DJ, et al. Preclinical characterization of a (S)-N-(4-cyano-3-trifluoromethylphenyl)-3-(3-fluoro, 4-chlorophenoxy)-2-hydroxy-2methyl-propanamide: a selective androgen receptor modulator for hormonal male contraception. Endocrinology 2009;150:385-95.

66. Dalton JT, Taylor RP, Mohler ML, et al. Selective androgen receptor modulators for the prevention and treatment of muscle wasting associated with cancer. Curr Opin Support Palliat Care 2013;7:345-51.

67. Jones A, Hwang DJ, Duke CB, et al. Nonsteroidal Selective Androgen Receptor Modulators Enhance Female Sexual Motivation. J Pharmacol Exp Ther 2010;334:439-48.

68. Miner JN, Chang W, Chapman MS, et al. An Orally Active Selective Androgen Receptor Modulator Is Efficacious on Bone, Muscle, and Sex Function with Reduced Impact on Prostate. Endocrinology 2007; 148:363-73.

69. Jones A, Hwang D-J, Narayanan R, et al. Effects of a Novel Selective Androgen Receptor Modulator on Dexamethasone-Induced and Hypogonadism-Induced Muscle Atrophy. Endocrinology 2010;151:3706-19.

70. Bosy-Westphal A, Eichhorn C, Kutzner D, et al. The age-related decline in resting energy expenditure in humans is due to the loss of fat-free mass and to alterations in its metabolically active components. J Nutr 2003;133:2356-62.

71. Crawford J. What are the criteria for response to cachexia treatment? Ann Palliat Med 2019;8:43-9.
72. Liu J, Motoyama S, Sato Y, et al. Decreased Skeletal Muscle Mass After Neoadjuvant Therapy Correlates with Poor Prognosis in Patients with Esophageal Cancer. Anticancer Res 2016;36:6677-85.

73. Chu MP, Lieffers J, Ghosh S, et al. Skeletal muscle density is an independent predictor of diffuse large B-cell lymphoma outcomes treated with rituximab-based chemoimmunotherapy. J Cachexia Sarcopenia Muscle 2017;8:298-304.

74. Sjøblom B, Gronberg BH, Wentzel-Larsen T, et al. Skeletal muscle radiodensity is prognostic for survival in patients with advanced non-small cell lung cancer. Clin Nutr 2016;35:1386-93.

75. Mühlberg W, Sieber C. Sarcopenia and frailty in geriatric patients: implications for training and prevention. $\mathrm{Z}$ Gerontol Geriatr 2004;37:2-8.

76. Permpongkosol S, Khupulsup K, Leelaphiwat S, et al. Effects of 8-Year Treatment of Long-Acting Testosterone Undecanoate on Metabolic Parameters, Urinary Symptoms, Bone Mineral Density, and Sexual Function in Men With Late-Onset Hypogonadism. J Sex Med 2016;13:1199-211.

77. Traish AM. Testosterone therapy in men with testosterone deficiency: are the benefits and cardiovascular risks real or imagined? Am J Physiol Regul Integr Comp Physiol 2016;311:R566-73.

78. Clark RV, Walker AC, Andrews S, et al. Safety, pharmacokinetics and pharmacological effects of the selective androgen receptor modulator, GSK2881078, in healthy men and postmenopausal women. Br J Clin Pharmacol 2017;83:2179-94.

79. GTx Reports Results for Enobosarm POWER Trials for the Prevention and Treatment of Muscle Wasting in Patients with Non-Small Cell Lung Cancer. 2013. Available online: https://www.businesswire.com/news/ home/20130819005378/en/GTx-Reports-ResultsEnobosarm-POWER-Trials-Prevention

80. Ramage MI, Skipworth RJE. The relationship between muscle mass and function in cancer cachexia: smoke and mirrors? Curr Opin Support Palliat Care 2018;12:439-44.

81. Temel JS, Abernethy AP, Currow DC, et al. Anamorelin in patients with non-small-cell lung cancer and cachexia (ROMANA 1 and ROMANA 2): results from two randomised, double-blind, phase 3 trials. Lancet Oncol 2016;17:519-31.

82. Fearon K, Argiles JM, Baracos VE, et al. Request for regulatory guidance for cancer cachexia intervention trials. 
J Cachexia Sarcopenia Muscle 2015;6:272-4.

83. Fearon K, Strasser F, Anker SD, et al. Definition and classification of cancer cachexia: an international consensus. Lancet Oncol 2011;12:489-95.

84. Grande AJ, Silva V, Maddocks M. Exercise for cancer cachexia in adults: Executive summary of a Cochrane Collaboration systematic review. J Cachexia Sarcopenia Muscle 2015;6:208-11.

85. Anahad OC. A Better Body in a Pill? Experts Urge Caution on SARMs. New York Times (Online) 2018.

86. Hansson A, Knych H, Stanley S, et al. Equine in vivoderived metabolites of the SARM LGD-4033 and comparison with human and fungal metabolites. J Chromatogr B Analyt Technol Biomed Life Sci 2018;10741075:91-8.

87. Van Wagoner RM, Eichner A, Bhasin S, et al. Chemical Composition and Labeling of Substances Marketed as Selective Androgen Receptor Modulators and Sold via the Internet. JAMA 2017;318:2004-10.

88. USADA Resolves Four Ostarine Cases Under the UFC

Cite this article as: Christiansen AR, Lipshultz LI, Hotaling JM, Pastuszak AW. Selective androgen receptor modulators: the future of androgen therapy? Transl Androl Urol 2020;9(Suppl 2):S135-S148. doi: 10.21037/tau.2019.11.02
Anti-Doping Policy. USADA. 2019. Available online: https://ufc.usada.org/usada-resolves-four-ostarine-casesunder-ufc-anti-doping-policy/ Accessed July 182019.

89. Fragkaki AG, Sakellariou P, Kiousi P, et al. Human in vivo metabolism study of LGD-4033. Drug Test Anal 2018;10:1635-45.

90. Piper T, Dib J, Putz M, et al. Studies on the in vivo metabolism of the SARM YK11: Identification and characterization of metabolites potentially useful for doping controls. Drug Test Anal 2018;10:1646-56.

91. Thevis $M$, Schänzer W. Synthetic anabolic agents: steroids and nonsteroidal selective androgen receptor modulators. Handb Exp Pharmacol 2010;(195):99-126.

92. Cacciola S, Vorkunov M. Noah Suspended for Failing a Doping Test: [Sports Desk]. New York Times. 2017 Mar 26.

93. What you need to know about Ostarine, the drug found in Wildcats star Allonzo Trier's system. Arizona Daily Star. 2018 February 23, 2018. 